\title{
RESEARCH ON THE MANUFACTURING MAGNESIUM FROM THANHHOA DOLOMITE BY PIDGEON PROCESS
}

\author{
Vu Viet Quyen \\ School of Mechanical Engineering ${ }^{l}$ \\ quyenvv.cndt@vimaru.edu.vn \\ Vu Thi Thu Trang \\ School of Mechanical Engineering ${ }^{l}$ \\ trangvtt.vck@vimaru.edu.vn \\ Nguyen Duong Nam \\ School of Mechanical Engineering ${ }^{l}$ \\ namnd.khcs@vimaru.edu.vn \\ Tran Duc Huy \\ School of Materials Science and Engineering ${ }^{2}$ \\ huy.tranduc@hust.edu.vn \\ Duong Ngoc Binh \\ School of Materials Science and Engineering ${ }^{2}$ \\ binh.duongngoc@hust.edu.vn \\ ${ }^{1}$ Vietnam Maritime University \\ 484 Lach Tray str., Hai Phong, Viet Nam \\ ${ }^{2}$ Hanoi University of Science and Technology \\ 1 Dai Co Viet St, Hai Ba Trung District, Ha Noi, Viet Nam
}

\begin{abstract}
The magnesium and magnesium alloys has applied widely in different industrial aspects in Vietnam in the modern life. Especially, the products from magnesium alloys implementing in the automotive have increased rapidly since the car elements tend to be generated by the light alloys in order to save the fuel. However, in the current time, Vietnam has no factories to produce the magnesium to adapt the domestic demand although it owns an enrich resource of raw materials. This research indicates the possibility of using the dolomite ore in Thanhhoa - Vietnam to make the magnesium as well as evaluate the primary factors like recovering temperature, reducing agent rate, recovering time having effect on the reduction efficiency of Thanhhoa dolomite by metallothermic method in vacuum (Pidgeon Process). This is basic process, low investment and suitable for the small and medium scales in Vietnam. The experiment includes heating, indicating the chemical ingredients and recovering experiment on the dolomite after calcination (dolime) by using ferrosilicon. The thermodynamic model is created to estimate the recovering efficiency in the Pidgeon. The result shows that the $\mathrm{CaO} / \mathrm{MgO}$ molar ratio of calcination dolomite in Thanhhoa is nearly 1.5 which is suitable to produce magnesium in the case of highly-required efficiency and pureness. Besides, the result from the furnace of the experiment is lower than the one in the model. The samples are set up to check the influence of the rate of ferrosilicon in the compound. The result indicates that the ideal efficiency reaches $85 \%$ with $30 \%$ ferrosilicon. Moreover, the study confirms that the optimal operating conditions in this process are recovering during three hours at $1200^{\circ} \mathrm{C}$ and $100 \mathrm{~Pa}$ pressure. This result proves the potential application of Thanhhoa dolomite in the industry suitable with the current condition in Vietnam.
\end{abstract}

Keywords: Recovering Magnesium, Vacuum Reduction, Thanhhoa Dolomite, Ferrosilicon, Pidgeon Process, FactSage Sofware.

DOI: $10.21303 / 2461-4262.2020 .001383$

\section{Introduction}

Magnesium is a kind of light metal and its density is $1.738 \mathrm{~g} / \mathrm{cm}^{3}$. In comparison with aluminum, it is equivalent two third while with steel it is equal a sixth. The applications of magnesium in the industry are diverse. It is used to produce the light and durable alloys for the aviation, mechatronic and automobile that leads to the rise in the magnesium utilization over this period $[1,2]$. 
According to the USGS report in 2015, the whole magnesium productivity in 2013 is 878.000 tones and the one in 2014 is 907.000 tones. Besides, the world magnesium request has climbed nearly $10 \%$ every year [3]. Take Vietnam as a typical example for this issue, the improvement of Supporting Industries leads to the rapid growth of magnesium and magnesium alloy request while magnesium and magnesium alloy are mostly imported. Event at this time in Vietnam, the number of research related to creation and evaluation the impacts of technical parameters in the composing magnesium process are few. Therefore, producing magnesium from the domestic source will not only adapt the magnesium demand but also be a way to use the natural resource probably. In the world, there are normally two approaches to produce magnesium including silicothermic method and magnesium chloride electrolytic melting [4]. Pidgeon, Mintek and Magnetherm are known as the most common processes of the thermal silica method. Meanwhile, Pidgeon process plays a crucial role in producing nearly $70 \%$ magnesium of the whole world over a time of recent 20 years that was created by a Canadian chemist $[5,6]$. This process is easy to apply with low workforce requisition and less expense as well comparing to the electrolysis [7]. In this process, magnesium metal is reduced from calcined dolomite under vacuum using ferrosilicon as a reducing agent [8]. The high temperature is released in the reducing reaction so it has no need for extra temperature in this process from the beginning step to the last one when the completed product is gotten in the self-staining condition [9].

The recent studies show that the rate of silicon in ferrosilicon has direct ratio with magnesium recovery efficiency. The higher rate of silicon has been in ferrosilicon, the more magnesium recovery is able to get. Nevertheless, the employment of ferrosilicon $>75 \%$ silicon has observed a decrease of silicon effectiveness. In a research related to the reducing reaction of dolomite with silicon, it has introduced the result related to the relationship of using the ferrosilicon $72-75 \%$ and $90 \%$ silicon with the recovery efficiency [10]. The final result has shown that there is no difference in applying two kinds of ferrosilicon. The ferrosilicon $0.72-0.75$ silicon reaches the agreement that it has mutual benefit for efficiency reaction and manufacture. Silica and coal are two main ingredients to make ferrosilicon. The foremost reaction to generate ferrosilicon:

$$
\mathrm{Fe}_{2} \mathrm{O}_{3(s)}+4 \mathrm{SiO}_{2(s)}+11 \mathrm{C}_{(s)} \rightarrow 2 \mathrm{FeSi}_{2(s)}+11 \mathrm{CO}_{(g)}, \Delta H=2096 \mathrm{~kJ} / \mathrm{mol} \mathrm{Fe}_{2} \mathrm{O}_{3}
$$

In the Pidgeon method, ferrosilicon is an extremely crucial substance in the process to reduce magnesium from ore like dolomite, the ferrosilicon producing money accounts for $50 \%$ in this procedure. The predicted ferrosilicon request and expense is deciding the almost the magnesium producing expense in the practice. Dolomite is the primary ore employing for this process. Since this kind of ore has the higher calcium oxide percentage comparing to magnesite, it has not generated the complex oxide $\mathrm{MgO} \cdot \mathrm{SiO}_{2}$. Thus, the amount of magnesium oxide attends in the procedure freely and the recovery efficiency go up dramatically [11]. The foremost reaction is shown below:

$$
2 \mathrm{CaO}_{(s)}+2 \mathrm{MgO}_{(s)}+(\mathrm{Fe}) \mathrm{Si}_{(s)} \rightarrow 2 \mathrm{Mg}_{(g)}+\mathrm{Ca}_{2} \mathrm{SiO}_{4(s)}+\mathrm{Fe}_{(s)}
$$

In the reducing reaction, they often use catalysts as an extra substance and $\mathrm{CaF}_{2}$ is the most common factor. Research of effect in a range of catalysts consisting of $\mathrm{CaF}_{2}, \mathrm{BaF}_{2}, \mathrm{MgF}_{2}$ with the similar percentage 2.5, calcium fluorides reaches the highest effect [10]. Nevertheless, the management of $\mathrm{CaF}_{2}$ implement in the procedure is an important factor. The liquid is generated by calcium fluorides promote the reaction race. Theoretically, in the temperature condition under $1000{ }^{\circ} \mathrm{C}$ the magnesium gas is formed. However, the solid- solid reactions slow down the reaction race under the low temperature condition $[12,13]$. The liquid phase is generated evenly on the surface of the oxide particle, it leads to the supply of silicon over the total briquettes. The calculation result about the role of $\mathrm{CaF}_{2}$ in the raw mixture in Fig. 1 proves that the amount of magnesium gas has no effect from added $\mathrm{CaF}_{2}$ [14]. The growth of calcium fluorides leads to the increase of the liquid generation so its role relates to the thermodynamic. In the practical field, the optimal limit of calcium fluorides to guarantee the continuous operation is $2-3 \%$.

This rate is ensuring the low density of liquid slag as well. In the current studies, there is a rich and inexpensive dolomite ore source in Vietnam that is reasonable for the rapid increase request. 
The manufacturing and workforce conditions have shown that the usage of Pidgeon in this region is suitable. The previous study indicates that the Thanhhoa dolomite with the 18-22\% magnesium oxide is proper for magnesium reducing reaction [11].

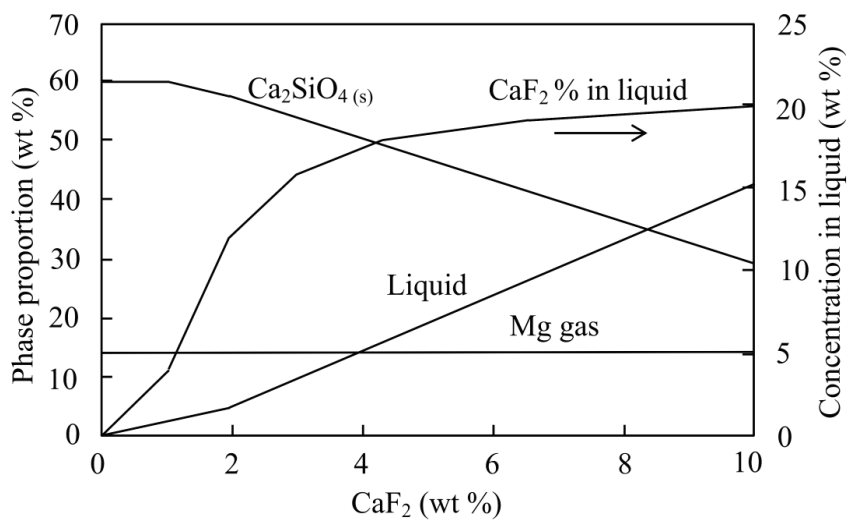

Fig. 1. Percentages of the fundamental stages and centralization of calcium fluorides in liquid [14]

In this study, the calculation of silicothermic processes are implemented the module Equilib in FactSage 7.2 to predict the ability of magnesium recovery. From the experimental results, the authors have researched the impact of several factors like temperature, the ratio of reductant, reduction time on the magnesium reducing procedure from Thanhhoa dolomite by using Pidgeon process.

\section{Material and Methods}

\section{1. Materials}

Thanhhoa is a province in Vietnam with the rich source of dolomite in Thanhhoa district approximately a million tones. The collected dolomite patterns in this experiment are investigated the chemical parameters with the resultant as in the Table $\mathbf{1 .}$

Table 1

Chemical composition in Thanhhoa dolomite ore

\begin{tabular}{cccccc}
\hline Component & $\mathrm{SiO}_{2}$ & $\mathrm{Fe}_{2} \mathbf{O}_{3}$ & MgO & CaO & LOI \\
\hline wt $(\%)$ & 0.3 & 0.15 & 23.12 & 33.04 & 43.39
\end{tabular}

The ferrosilicon from China provided by ManhHung Co., Ltd. has the ingredients' rate with $72 \% \mathrm{Si}, 27 \% \mathrm{Fe}, 0.1 \% \mathrm{C}, 0.03 \% \mathrm{P}, 0.02 \% \mathrm{~S}$. Its grinded particle has the dimension with $100 \mu \mathrm{m}$ that are mixed with calcium fluorides $(3 \%)[14,15]$. The ore is heat under the temperature of $1000{ }^{\circ} \mathrm{C}$ in order to decompose the carbon dioxides and water and get two kind of oxides including magnesium oxide $37.28 \%$ and calcium oxide $54.8 \%$ (Fig. 2). Then, the reducing procedure will be started. The primary calcination process is shown below:

$$
\mathrm{CaCO}_{3} \cdot \mathrm{MgCO}_{3} \rightarrow \mathrm{MgO}_{(s)}+\mathrm{CaO}_{(s)}+2 \mathrm{CO}_{2(g)} .
$$

The starting temperature for dissolution of $\mathrm{MgCO}_{3}$ and $\mathrm{CaCO}_{3}$ is $530{ }^{\circ} \mathrm{C}$ and $830{ }^{\circ} \mathrm{C}$, respectively.

The product after calcination step is crushed and mixed with two kinds of substances including ferrosilicon and calcium fluorides with the ingredients' rate in the Table 2.

The rate of calcium fluorides in this test is $3 \%$. Then, the compound is pressed under the pressure $3 \mathrm{MPa}$ to create a briquette having capacity $14 \mathrm{~mm}$ diameter, $20 \mathrm{~mm}$ height, $11 \mathrm{~g}$ mass. 


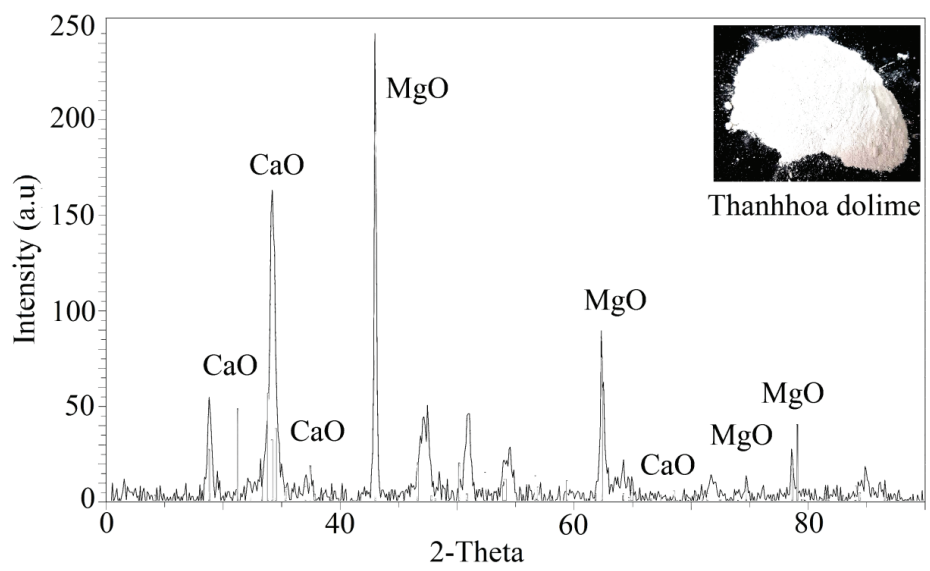

Fig. 2. XRD pattern of Thanhhoa dolomite

Table 2

The investigation of the impacts of ferrosilicon on the recovering magnesium

\begin{tabular}{cccc}
\hline & & Component Of Briquette, wt \% & \\
\cline { 2 - 4 } & Fe-Si & Dolomite & $\mathbf{C a F}_{\mathbf{2}}$ \\
\hline Sample 1 & 17 & 80 & 3 \\
Sample 2 & 20 & 77 & 3 \\
Sample 3 & 25 & 72 & 3 \\
Sample 4 & 30 & 57 & 3 \\
Sample 5 & 40 & 47 & 3
\end{tabular}

\section{2. FactSage software}

The Equilib module of FactSage software with the Gibbs energy minimization technique is used to calculate the equilibrium of the reaction [16]. This package has optimal database for solutions like metals, oxides and slags. The data of pure elements are getting from the thermochemical tables JANAF, thermodynamic property data from Barin and the solution for liquid slag from Erikkson [17-20]. For this process equilibrium calculation, the initiate data include $70 \%$ dolomite and $30 \%$ ferrosilicon as Sample 4 in Table 2. The equilibrium is evaluated at $1200{ }^{\circ} \mathrm{C}$ and $100 \mathrm{~Pa}$. In comparison with the experiment, the catalyst $\mathrm{CaF}_{2}$ has not been in the model due to its unique role in the kinetics and it has no effect on the equilibrium [20]. The equilibrium calculation model has applied the single-stage method [20,21]. Moreover, the database has selected the FactsPS to calculate vapour, FToxid is used to evaluate the oxide reducing reaction and FTlite analyzes the magnesium and non-ferrous metal.

\section{3. Experimental}

The Fig. 3 has the furnace schematic diagram of the Pidgeon process that built on the basis of the furnace diagram at Mintek laboratory [18]. Due to extending the communicating area among the reacting elements, the previous compound is pressed into the cylindrical shapes. The final product of reducing procedure including the magnesium gas in the cooling space and the waste having combination of $\mathrm{Ca}_{2} \mathrm{SiO}_{4}$ and $\mathrm{Fe}$. The magnesium in this stage is the product of the squeezed process so it is extraordinarily pure. Next, the product is deliquesced and excluded the contamination to increase the pureness. This process has done by set. The furnace has employed in this procedure with the stainless steel tube $310 \mathrm{~S}$, which is often called reducing pipe or retort. Its diameter is $6.5 \mathrm{~cm}$ and its length is $105 \mathrm{~cm}$. It is allocated inner the furnace having heating elements made of silicon carbide. 
The retort is two-headed type, vacuum system and inert gas are communicated with each other. Vacuum pump and some equipment like pressure sensor and temperature recorder are connected to make a completed vacuum system. Alumina bricks are used to make the furnace be an insulating part. The temperature the furnace is adjusted by a temperature controller with two thermocouples inside and outside this equipment. The temperature and pressure are two important factor of this procedure so they are continuously recorded throughout this process. The circulating liquid is used to keep the temperature at the magnesium condensation section around $300-400{ }^{\circ} \mathrm{C}$.

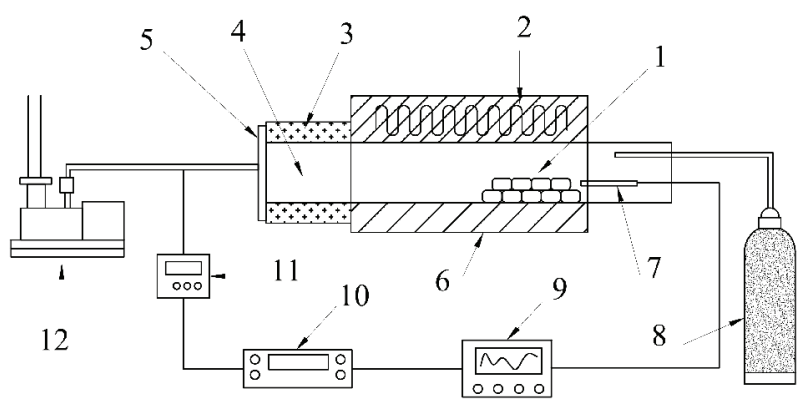

Fig. 3. The furnace diagram:

1 - Briquettes; 2 - Heating elements; 3 - Cooling water; 4 - Mg condensation section;

5 - Stainless steel retort; 6 - Furnace; 7 - Thermocouple; 8 - Argon gas; 9 - Temperature measuring unit; 10 - Power supply; 11 - Pressure gauge; 12 - Vacuum pump

The furnace of recovering magnesium is shown in Fig. 4. Four samples shown in Table 2 are used to evaluate the impacts of ferrosilicon on the magnesium reducing procedure at the temperature $1200^{\circ} \mathrm{C}$. The experimental samples are arranged horizontally according to the Fig. 3 . After arranging step, the furnace is terminated and set up the reacting condition with vacuum pressure is $100 \mathrm{~Pa}$ and the leaking factor is approximately $500-600 \mathrm{~mm}^{3} / \mathrm{min}$. When the leaking factor is fixed, the furnace temperature is pushed to $700{ }^{\circ} \mathrm{C}$ in around two hours in order to eliminate the wet or the rest carbon dioxide in the reacted substances. After finishing this stage, the temperature of the furnace continued to be raised to the reducing temperature in the following three hours.

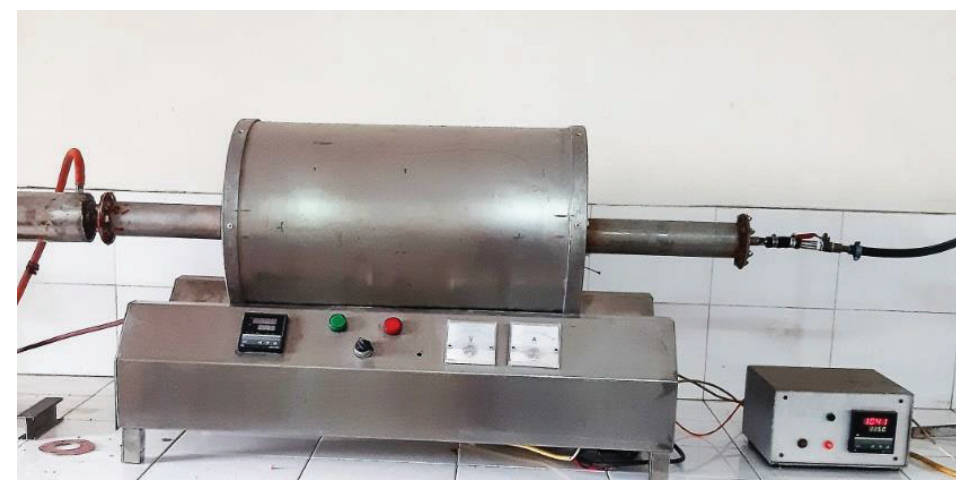

Fig. 4. The furnace of recovering magnesium

After the recovering process, the furnace and the vacuum pumping system is off, the inert gas (Ar gas) is pumped to the inner of retort to push the system pressure to atmospheric as well as to protect magnesium condensation. It just stops adding the inert gas when the furnace turn to the room temperature and the final product is analyzed. The general flowchart of reduction of magnesium from Thanhhoa dolomite ore by using Pidgeon process is shown in Fig. 5.

To make deep research in the impacts of temperature on the process, the model in Sample 4 having ferrosilicon ratio $30 \%$ is heat at the five level of temperature from 1000 to 1400 and each level differs $100{ }^{\circ} \mathrm{C}$. In order to survey the effect of time, the recovery reaction is applied in a range of time from 1 to 4.5 hours with the Sample 4 with the above ingredients. 


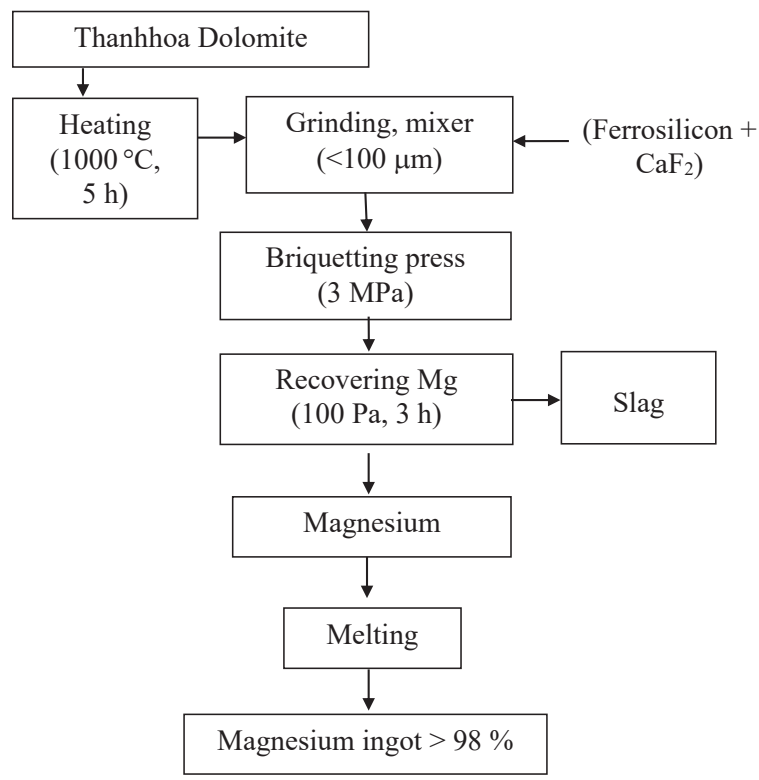

Fig. 5. Pidgeon process diagram

The formula of magnesium reducing efficiency:

$$
\text { Reduction Efficiency }(\%)=\frac{w_{1}-w_{2}}{w_{1}} \cdot 100
$$

where $w_{1}$ is the mass of the magnesium of the briquettes before the recovery; $w_{2}$ is the mass of the magnesium of the briquettes residue after the recovery.

The silicon efficiency formula presented by Pidgeon and Alexander as below [23]:

$$
\text { Silicon Efficiency }(\%)=\frac{\text { weight of collected } \mathrm{Mg}}{\text { weight of } \mathrm{Mg} \text { equivalent of Si present }} \cdot 100 \% \text {. }
$$

The dolime, calcium fluoride and ferrosilicon powder mixture was mixed, milled by a vertical planetary ball mill NQM-4 of Yangzhou Nuoya Machinery Co., Ltd., The chemical compositions of dolomite and magnesium crown analyzed by using chemical analysis techniques and X-ray fluorescence (XRF) spectrometer Bruker S4 - Pioneer. To identify the phase changes in the briquettes after vacuum recovery, the phase compositions are determined by PANalytical Empyrean X-ray diffraction spectroscopy, the SEM images of the magnesium crown by SEM JEOL Model JSM-6490.

\section{Research results}

Calculation results by FactSage. The estimated results about the ability of magnesium recovery from Thanhhoa dolomite by FactSage has shown in the Fig. 6. The recovery efficiency in the equilibrium is $91.3 \%$ and the magnesium purity is extremely high $99.7 \%$.

The impurities with low proportion in dolime is not calculated, so in the equilibrium $\alpha-\mathrm{Ca}_{2} \mathrm{SiO}_{4}$ is the main phase in slag. Besides, there are other phases like periclase phase $-\mathrm{MgO}$, lime phase $\mathrm{CaO}$ and redundancy of $\mathrm{Fe}-\mathrm{Si}$. The gas phase consists of $99.7 \% \mathrm{Mg}$, the impurities like $\mathrm{Ca}$ and $\mathrm{SiO}$.

Experimental results. After the reduction process, the surface of the briquettes is shown in Fig. 7, a. The widened holes and new ones will be created by the magnesium gas expanding through the old ones after the reducing process finishes. Then, the magnesium gas will focus on the briquettes surface before being absorbed in the rear of the furnace and condense at the low temperature section. The location of magnesium metal condenses depends on the pressure of vacuum and pressing force. There are three areas being able to its location like cooling area, furnace border and briquette area (Fig. 7, b). The solid magnesium will selected in pieces and the remains on the wall are small crystals and flammable. 


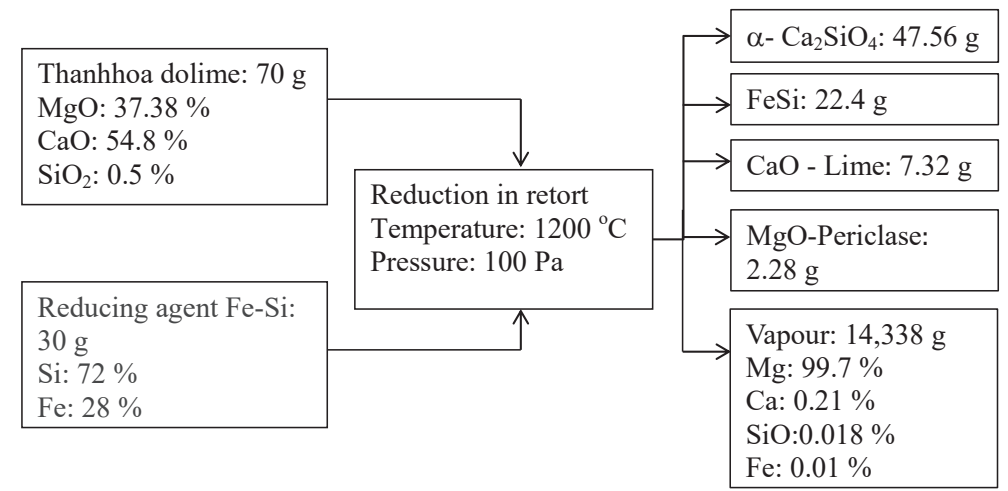

Fig. 6. Prediction of reduction by Thanhhoa dolime

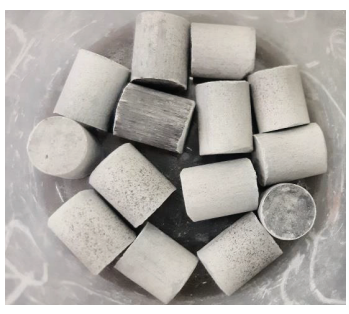

$a$

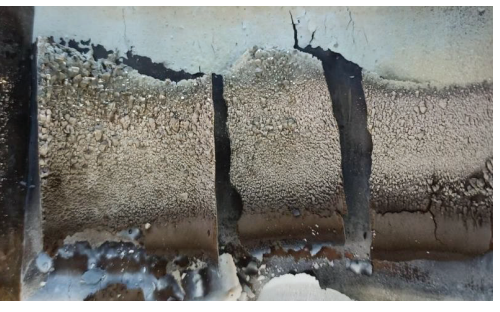

$b$

Fig. 7. Products obtained after the reduction process:

$a$ - the briquettes after recovering; $b$ - recovered crown magnesium in the cooling space

The Fig. 8 shows the impact of ferrosilicon ratio on the reducing procedure efficiency under the temperature condition of $1200{ }^{\circ} \mathrm{C}$. The graph has shown that ferrosilicon $30 \%$ will help the procedure to get the largest reduction. The cleanness of magnesium metal getting back from the mixture in the above sample is $94.3 \%$. While the ferrosilicon $20 \%$ reaches the efficiency $64 \%$, this resultant is not as high as the one getting by $\mathrm{B}$. Mehrabi and several other researches [22]. The uneven mixing of briquettes in the briquettes is one of the evidence of low efficiency. In the following experiment, this one is eliminated in order to reach the similar results with other researches. As mentioned above, the estimated model ignores the effects of dolomite and ferrosilicon, so in the experimental result with $30 \% \mathrm{Fe}-\mathrm{Si}$ the pureness is lower than the model resultant having $99.7 \%$.

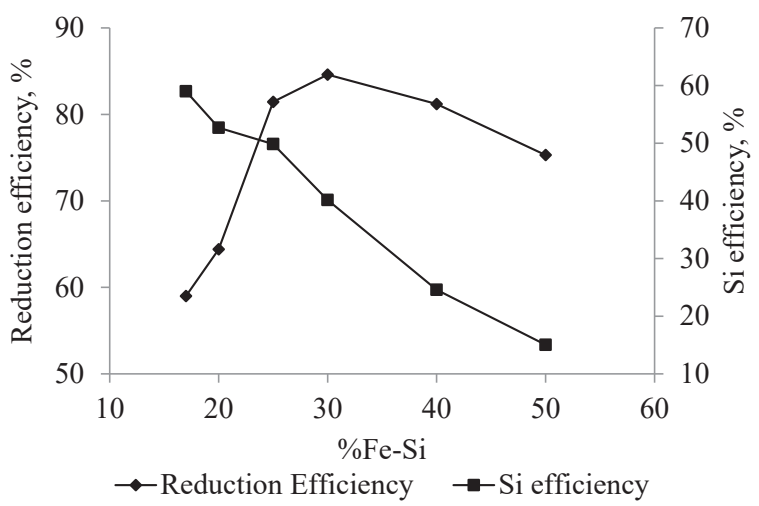

Fig. 8. The impacts of the recovering substance proportion in subtracting magnesium

The Fig. 9 has shown the impact of temperature on the reducing process productivity in case of ferrosilicon $30 \%$. It proves that the temperature and productivity has direct ratio. The temperature of a thousand degree Celsius will have the efficiency $70 \%$, if it increases by $200{ }^{\circ} \mathrm{C}$ the efficiency will be $85 \%$. This efficiency remains at that number even the temperature go up higher. The reducing reaction is extremely productive when the temperature is higher than $1080{ }^{\circ} \mathrm{C}$. There are two phases: 
the vaporization of magnesium in the form of liquid and the new product in gas form. The consolidation between them is the main factor to rise the acting race. The equations show the changes of these phases:

$$
\mathrm{Mg} \text { (liquid) } \rightarrow \mathrm{Mg} \text { (gas) and } \mathrm{MgO} \text { (solid) }+\mathrm{Si} \text { (solid) } \leftrightarrow \mathrm{SiO}_{2} \text { (solid) }+2 \mathrm{Mg} \text { (gas). }
$$

The magnesium mobility depends on the temperature and the higher temperature leads to the high speed of magnesium mobility when the efficiency remains unchanged. It takes three hours to have the efficiency $85 \%$ with the ideal circumstance at $1200-1400{ }^{\circ} \mathrm{C}$.

A crucial element of the reducing process is time with the below responsibilities: Reaching the temperature uniformity from the surface to the inside of the briquettes, ensure the process acting form in to out of the briquettes, in order to make the magnesium evaporating from the briquettes to the condensation section.

This study used Sample 4 sample in Table 2 to study the effect of the time on the reduction process at $1200{ }^{\circ} \mathrm{C}$. The reducing time varies between an hour to four and a half hours with the premium choice is three hours. As shown in the Fig. 10, in a period of three hours, the magnesium reducing productivity has a sharp increase due to the growth of the substances' reaction during this time. After the third hour with the reaction productivity of $84.6 \%$, then, it slows down the speed and remains stable even under the increase temperature condition. Due to this relationship between the time and productivity and fabricating expense, it is necessary to determine the time of reducing process.

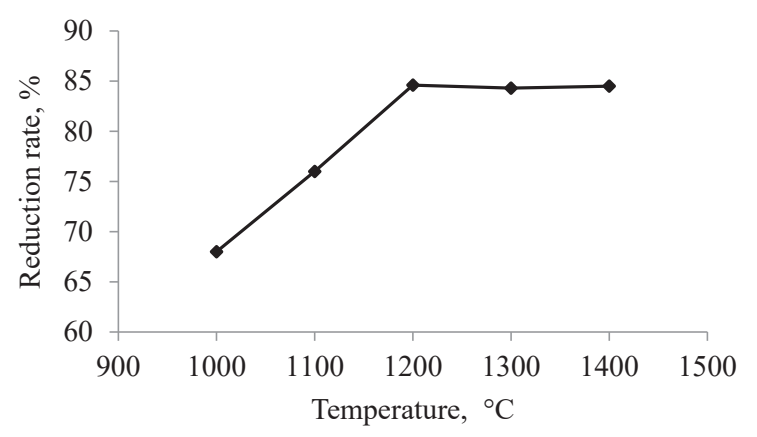

Fig. 9. The impacts of temperature on subtracting magnesium

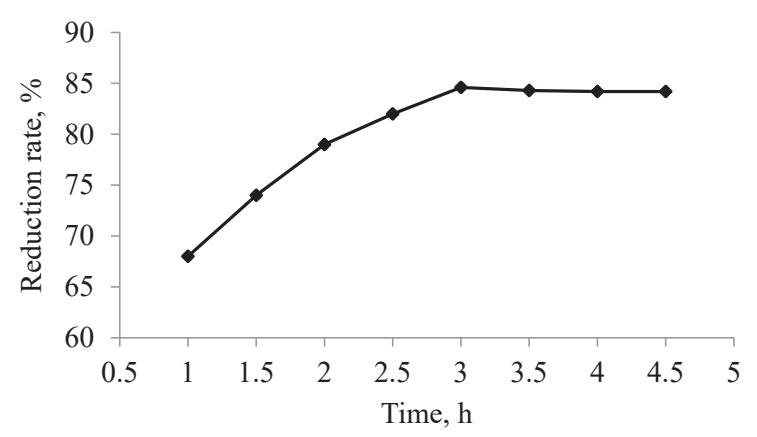

Fig. 10. The time impacts on subtracting magnesium

\section{Discussion of results}

The primary calculation by FactSage software has indicated that it is possible to use Thanhhoa dolomite to produce magnesium. Nevertheless, this estimation is in the ideal equilibrium and ignores the consideration of impurities. Thus, the efficiency and pureness of condensation magnesium in the mathematical model is significantly higher than the one in the experiment.

The analysis of experiment results show that the optimum efficiency is reached when the ingredients has ferrosilicon $30 \%$. It can be proved by the recovering reactions:

$$
2 \mathrm{CaO}_{(s)+} 2 \mathrm{MgO}_{(s)+} \mathrm{Si}_{(s)} \rightarrow 2 \mathrm{Mg}_{(g)}+\mathrm{Ca}_{2} \mathrm{SiO}_{4(s)} .
$$


The formula (4) has shown that in the equilibrium the combination is created according to the below rates and their weights in this compound:

$$
\begin{gathered}
\mathrm{CaO}=56 \mathrm{~g} / \mathrm{mol} \times 2 \mathrm{~mol}=112 \mathrm{~g} ; \\
\mathrm{MgO}=40 \mathrm{~g} / \mathrm{mol} \times 2 \mathrm{~mol}=80 \mathrm{~g} ; \\
\mathrm{Si}=28 \mathrm{~g} / \mathrm{mol} \times 1 \mathrm{~mol}=28 \mathrm{~g} ; \mathrm{Fe}-\mathrm{Si}(72 \% \mathrm{Si})=100 / 72 \times 28 \mathrm{~g}=38.8 \mathrm{~g} ;
\end{gathered}
$$

Rate $\mathrm{CaO}: \mathrm{MgO}:(\mathrm{Fe}, \mathrm{Si}) 72 \%=48.52: 34.66: 16.81$.

Thus, the stable ferrosilicon ratio ( $72 \%$ silicon) is $17 \%$. When the amount of ferrosilicon increases, contacting area of reductant with magnesium climbs rapidly. Thus, the efficiency percentage becomes higher as well. Nevertheless, in the ferrosilicon 40-50\%, there is a problem that the amount of $\mathrm{Si}$ is higher than expectation. This redundant silica is able to have reaction with oxygen or magnesium to create the new oxide or magnesium metasilicate. It leads to the reduction of magnesium metal. Meanwhile, the silicon dioxide is capable of reacting with calcium oxide to create the new combination with high viscosity in the residue that makes magnesium mobility hard and the efficiency low. In addition, the efficiency of Si decreases sharply when the rate of $\mathrm{Fe}-\mathrm{Si}$ increases. It leads to an increase in the reducing process costing the manufacturing. It is necessary to consider the rate of $\mathrm{Fe}-\mathrm{Si}$ in the industrial procedure from two sides.

The analysis about the impact of temperature on the process efficiency in this experiment (Fig. 9) shows that it get the higher efficiency than the one using dolomite of Turkey although the recovering time is less than [24]. Since the briquettes have the small shape but also the recovering pipe has and the quantity of briquettes every heating time are restricted. In addition, the location of briquettes is arranged in order to be near the heating space and getting the heat of radiation.

The time which the reducing reaction reaches the equilibrium has close connection with the reduction rate and the main impact factor of reduction rate like temperature. The reducing $\mathrm{MgO}$ is an endothermic reaction so the higher reducing temperature will lead to the faster reducing speed, shorten the time backing to equilibrium and higher recovering ratio of $\mathrm{MgO}$ in the fixed reacting period. The results in Fig. 10 have shown resultant indicates that the beneficial factors for reducing magnesium process like temperature, ferrosilicon percentage has just pushed the productivity to a stable level and stayed at this point to the end of process. It means that there is a magnesium oxide residue in the briquettes not joining in the reducing reaction. There are several theory around this problem and the most popular one is due to the combination of magnesium oxide with $\mathrm{Ca}_{2} \mathrm{SiO}_{4}$ in the formula (1) to create the new oxide $\mathrm{Ca}_{3} \mathrm{Mg}\left(\mathrm{SiO}_{4}\right)_{2}$ (merwinite).

Fig. 11 indicates the XRD analysis of the slag after recovering at $1200{ }^{\circ} \mathrm{C}$ during 3 hours with $30 \% \mathrm{Fe}-\mathrm{Si}$. It proves that $\mathrm{Ca}_{2} \mathrm{SiO}_{4}$ is the main phase in the slag, besides there is an existence of merwinite. This compound is constant at the recovering temperature and it will keep an amount of magnesium in the slag to limit the reaction of magnesium oxide [25].

The SEM images of the magnesium crown getting from the experiment of Sample 4 at the recovering temperature $1200{ }^{\circ} \mathrm{C}$ and $1300{ }^{\circ} \mathrm{C}$ are shown in Fig. 12. This analysis illustrates that at $1300{ }^{\circ} \mathrm{C}$, magnesium crowns has more impurities congealed on the surface than the one in the crystals at $1200{ }^{\circ} \mathrm{C}$. It proves that increasing the recovering temperature will push the reducing speed but it leads to the growth of impurities in magnesium crown and the later complicated refination. Thus, the recovering temperature using in this process is around $1200{ }^{\circ} \mathrm{C}$.

The ideal recovering efficiency of magnesium from Thanhhoa dolomite applying the Pidgeon is $84.6 \%$. In comparison with results of the magnesium recovering by other dolomites from Iran, Turkey with efficiency from $76-79 \%$, it is possible to implement this source and Pidgeon method in the industry. The Pidgeon has less high-tech requirement and low investment. However, it wastes a huge energy especially, the exhausts after the process have significant effect on the environment. In order to solve this problem, many experts around the world focus on improving the procedure by using another kind of reducing agent with higher efficiency than ferrosilicon. 


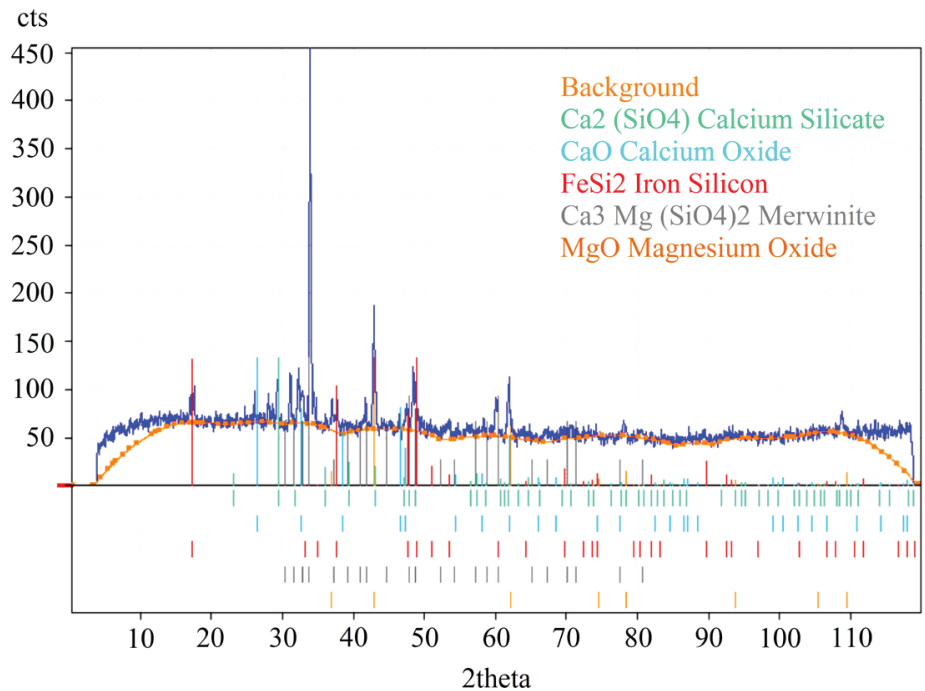

Fig. 11. XRD patterns of slag $\left(1200^{\circ} \mathrm{C}, 100 \mathrm{~Pa}\right)$

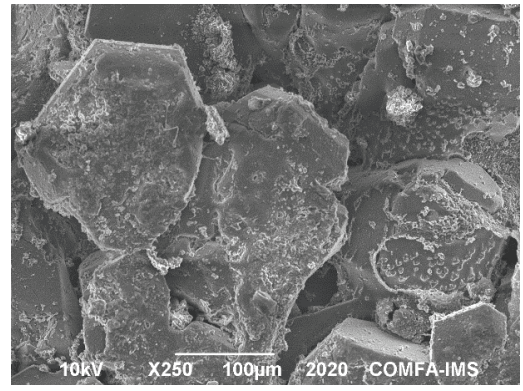

$a$

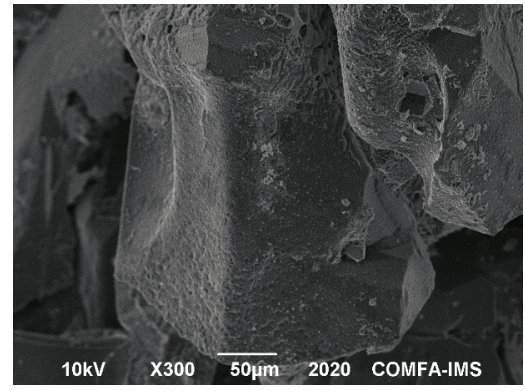

$b$

Fig. 12. Scanning electron microscope (SEM) image of magnesium crown: $a-1300{ }^{\circ} \mathrm{C} ; b-1200{ }^{\circ} \mathrm{C}$

\section{Conclusions}

The results predicted by FactSage simulation have proved that it is possible to produce magnesium from Thanhhoa dolomite. In term of the experiment, the similar result is get with ferrosilicon $30 \%$ at $1200{ }^{\circ} \mathrm{C}, 100 \mathrm{~Pa}$ and highest efficiency $84.6 \%$, the magnesium pureness before purifying is $94 \%$. This results show the possibility of using Thanhhoa dolomite to produce magnesium suitable with Vietnam condition.

The ferrosilicon $30 \%$ is ideal for the recovery process, however, the effective coefficient of Si decreases when the reducing agent ratio increases. Thus, the manufacturers should consider two factors in the production. The restricted efficiency is due to amount of $\mathrm{MgO}$ not attending in the silicothermic reaction and the combination of magnesium oxide with $\mathrm{Ca}_{2} \mathrm{SiO}_{4}$ to create the new oxide $\mathrm{Ca}_{3} \mathrm{Mg}\left(\mathrm{SiO}_{4}\right)_{2}$. The current simulation just includes the main ingredients of raw material. It is important to take deep research in the effect of impurities in material on the process and replace ferrosilicon by another more effective reducing agent.

\section{Acknowledgments}

Thanks to the supports from School of Mechanical Engineering - VMU, School of Materials Science And Engineering - HUST and experiment facilities from Prof. Tran Duc Huy's lab. This is appreciated acknowledgment for me to complete this study.

\section{References}

[1] Kainer, K. U. (2016). Challenges for Implementation of Magnesium into More Applications. Magnesium Technology 2016, 5-6. doi: https://doi.org/10.1007/978-3-319-48114-2_1 
[2] Brooks, G., Cooksey, M., Wellwood, G., Goodes, C. (2007). Challenges in light metals production. Mineral Processing and Extractive Metallurgy, 116 (1), 25-33. doi: https://doi.org/10.1179/174328507x163733

[3] Mineral commodity summaries 2015 (2015). U.S. Geological Survey. doi: https://doi.org/10.3133/70140094

[4] Wang, Y., You, J., Peng, J., Di, Y. (2016). Production of Magnesium by Vacuum Aluminothermic Reduction with Magnesium Aluminate Spinel as a By-Product. JOM, 68 (6), 1728-1736. doi: https://doi.org/10.1007/s11837-016-1865-6

[5] Bugdayci, M., Turan, A., Alkan, M., Yucel, O. (2018). Effect of Reductant Type on the Metallothermic Magnesium Production Process. High Temperature Materials and Processes, 37 (1), 1-8. doi: https://doi.org/10.1515/htmp-2016-0197

[6] Zang, J. C., Ding, W. (2013). The Pidgeon Process in China and Its Future. Magnesium Technology 2001, 7-10. doi: https:// doi.org/10.1002/9781118805497.ch2

[7] Cherubini, F., Raugei, M., Ulgiati, S. (2008). LCA of magnesium production. Resources, Conservation and Recycling, 52 (8-9), 1093-1100. doi: https://doi.org/10.1016/j.resconrec.2008.05.001

[8] Habashi, F. (1997). Handbook of Extractive Metallurgy. Vol. 2. Wiley, 2379.

[9] Halmann, M., Frei, A., Steinfeld, A. (2008). Magnesium Production by the Pidgeon Process Involving Dolomite Calcination and $\mathrm{MgO}$ Silicothermic Reduction: Thermodynamic and Environmental Analyses. Industrial \& Engineering Chemistry Research, 47 (7), 2146-2154. doi: https://doi.org/10.1021/ie071234v

[10] Toguri, J. M., Pidgeon, L. M. (1962). High-temperature studies of metallurgical processes: Part II. The thermal reduction of calcined dolomite with silicon. Canadian Journal of Chemistry, 40 (9), 1769-1776. doi: https://doi.org/10.1139/v62-271

[11] Chieu, L. T. (2017). Final report: Research and manufacture of metal magnesium from Vietnam magnesite ore by vacuum method. Ministry of Industry and Trade.

[12] Chen, M., Zhao, B. J., Chen, Y. H., Han, F. L., Wu, L. E. (2017). Reaction Mechanisms in the Silicothermic Production of Magnesium. The Minerals, Metals \& Materials Series, 239-249. doi: https://doi.org/10.1007/978-3-319-51091-0_22

[13] Wang, Y.-W., Zhao, K., Peng, J.-P., Di, Y.-Z., Li, Y.-L., Song, Y., Deng, X.-Z. (2014). Process of producing magnesium by thermal vacuum reduction using silicocalcium as reductant. Rare Metals, 35 (7), 571-575. doi: https://oi.org/10.1007/ s12598-014-0321-4

[14] Wang, C., Zhang, C., Zhang, S. J., Guo, L. J. (2015). The effect of CaF2 on the magnesium production with silicothermal process. International Journal of Mineral Processing, 142, 147-153. doi: https://doi.org/10.1016/j.minpro.2015.04.017

[15] Bale, C. W., Bélisle, E., Chartrand, P., Decterov, S. A., Eriksson, G., Gheribi, A. E. et. al. (2016). FactSage thermochemical software and databases, 2010-2016. Calphad, 54, 35-53. doi: https://doi.org/10.1016/j.calphad.2016.05.002

[16] Stull, D. R., Prophet, H. (1971). JANAF thermochemical tables, second edition. NSRDS. doi: https://doi.org/10.6028/nbs.nsrds.37

[17] Barin, I. (1993). Thermochemical data of pure substances. Vol. I. Weinheim Germany: VCH Verlagsgesellschaft mbH.

[18] Eriksson, G., Wu, P., Pelton, A. D. (1993). Critical evaluation and optimization of the thermodynamic properties and phase diagrams of the $\mathrm{MgO}-\mathrm{Al}_{2} \mathrm{O}_{3}, \mathrm{MnO}-\mathrm{Al}_{2} \mathrm{O}_{3}, \mathrm{FeO}-\mathrm{Al}_{2} \mathrm{O}_{3}, \mathrm{Na}_{2} \mathrm{O}-\mathrm{Al}_{2} \mathrm{O}_{3}$, and $\mathrm{K}_{2} \mathrm{O}-\mathrm{Al}_{2} \mathrm{O}_{3}$ systems. Calphad, 17 (2), $189-205$. doi: https://doi.org/10.1016/0364-5916(93)90019-8

[19] Wulandari, W., Rhamdhani, A., Brooks, G., Monaghan, B. J. (2009). Distribution of impurities in magnesium via silicothermic reduction. Proceedings of European Metallurgical Conference. Innsbruck, 1401-1415.Han, J.-W., Baek, U.-H., Lee, B.-D., Lee, K.-W., Han, G.-S. (2016). Study of the Thermal Reduction Behavior of Dolomite by the Pidgeon process. Korean Journal of Metals and Materials, 54 (2), 104-112. doi: https://doi.org/10.3365/kjmm.2016.54.2.104

[20] Mehrabi, B., Abdellatif, M., Masoudi, F. (2012). Evaluation of Zefreh Dolomite (Central Iran) for Production of Magnesium via the Pidgeon Process. Mineral Processing and Extractive Metallurgy Review, 33 (5), 316-326. doi: https://doi.org/10.1080/ 08827508.2011.601478

[21] Pidgeon, L. M., Alexander, W. A. (1944). Thermal Production of Magnesium Pilot plant Studies on the Retort Ferrosilicon Process. Transaction of the AIME, 159, 315-351.

[22] Yucel, O., Yiğit, S., Derin, B. (2005). Production of Magnesium Metal from Turkish Calcined Dolomite Using Vacuum Silicothermic Reduction Method. Materials Science Forum, 488-489, 39-42. doi: https://oi.org/10.4028/www.scientific.net/ msf.488-489.39

[23] Wynnyckyj, J. R., Tackie, E., Chen, G. (1991). The Problem of Limited Recoveries in the Pidgeon Process for Magnesium Production. Canadian Metallurgical Quarterly, 30 (3), 139-143. doi: https://doi.org/10.1179/cmq.1991.30.3.139 